\title{
The effects of competition teaching on the motivation of the high school students
}

\author{
Chunqing Wang ${ }^{1, a}$, Xiaofang $\mathrm{Hu}^{1, \mathrm{~b}}$ \\ ${ }^{1}$ School of Physical Education, Shaanxi Normal University, Shaanxi 710119, China; \\ à1351909580@163.com, b347801011@qq.com
}

Keywords: competition teaching, exercise motivation, basketball.

\begin{abstract}
To examine the effects of competition teaching on exercise motivation of high school boys, we practiced this teaching mode in basketball teaching in both the intervention and control groups. The results show that the participation tendency and avoidance tendency were significant different before and after the experiment. This indicated that the high school boys' basketball motivation after the game teaching intervention could be significantly improved. As a teaching method to promote students' study motivation, competition teaching mode involved the characteristics of students' physical and mental development. The teacher should carefully select and plan the contents of the competition, making full use of the existing venues and equipment, and organize competitions scientifically, to cultivate the students' awareness of sports and the right participation motivation.
\end{abstract}

\section{Introduction}

Physical education is not only an important part of school education, but an important condition to ensure students' healthy growth. Traditional teaching methods focus on imparting skills to the students. The students can directly learn the essence of the movement, but the teaching content is boring, which cannot effectively arouse students' interest in learning. The students' study motivation is not strong, so the way to improve students' learning motivation is needed. Game teaching method is the competition training method in the physical education class. The interpretation of the game training method refers to the teaching method according to the mode and rules of competition under the condition of simulation or real, strict and approximate competition [1]. Human beings are born with the sense of performance and competition, which will be more inclined to express themselves. Competition teaching method may promote students' active participation in learning and training, thus improving students' learning motivation and improving teaching effect. In this study, the competition teaching method was used to intervene in the basketball lessons of high school students, so as to verify the difference between the game teaching method and the motivation of basketball participation in high school students. This may enhanced the theoretical basis for PE teaching of PE teachers.

\section{Methods}

The subjects were all from No.13 middle school of Dalian city. A convenient sampling method is adopted in the selection process of the subjects. The subjects were 40 people with an average age of 18.73 and were in good physical condition. The subjects were divided into two classes, 20 each. Subjects were grouped according to their sports scores. There was no significant difference between the two groups of subjects.

According to the research content and purpose, we used the questionnaire of basketball motivation scale. Two surveys were conducted before and after intervention. The basketball motivation scale was used to score the score. To verify the influence of the competition teaching method on the sports motivation of high school boys. Excel 2007 and SPSS 21.0 software were used to calculate the experimental data obtained. In order to verify that the game teaching method has a certain effect on the students' motor motivation in the basketball game, the paired sample $\mathrm{T}$ test was conducted for the experimental group and the control group. $\mathrm{P}<0.05$ was considered statistically significant. Before 
the experiment, 40 questionnaires were issued and 40 questionnaires were collected. The questionnaire efficiency reached $100 \%$. After the experiment, 40 questionnaires were issued and 40 questionnaires were collected, and the questionnaire efficiency reached $100 \%$.

The experimental intervention was divided into three parts: the first part was to learn the muscle and joint stretching related to basketball, and to study basic techniques. The second part of the basic technical competition, the study of the content design into the competition for testing. A total of four projects were tested. The first item is the 28 meter dribble time match. Start dribbling from the bottom line to the bottom line. The second item is the dribbling past time. The site has eight poles. Start dribbling from the bottom line to the bottom line. The third one is a fixed-point shot, five points, one shot per point, and the percentage. The fourth item is the full - time round trip to the basketball game. Start dribbling to the opposite layup from the bottom line and return to the basket. The third part is a half - half match. The students were divided into five groups of four, and the group was divided against each other. A cycle race between groups. During the competition, teachers and students communicate and explain error correction.

The control group. Teaching in three steps. The first step is to learn about the muscles and joints involved in basketball, and to learn basic techniques. The second group carries out the basic technique practice. The third part is a half - court basketball game.

\section{Results}

Table 1 List of participation tendencies $(n=40)$

\begin{tabular}{clccc}
\hline & \multicolumn{1}{c}{$\mathrm{N}$} & $\mathrm{M}+\mathrm{SD}$ & $\mathrm{P}$ \\
\hline $\begin{array}{c}\text { Experimental } \\
\text { group }\end{array}$ & $\begin{array}{l}\text { Prior } \\
\text { participation } \\
\text { After a tendency to } \\
\text { participate }\end{array}$ & 40 & $6.60 \pm 3.59$ & $<0.05$ \\
$\begin{array}{l}\text { Prior } \\
\text { Experimental } \\
\text { group }\end{array}$ & $\begin{array}{l}\text { participation } \\
\text { After a tendency to } \\
\text { participate }\end{array}$ & 40 & $7.75 \pm 4.48$ & \\
\hline
\end{tabular}

It can be seen from table 1 that there was a significant change in the number of high school boys in the experimental group before and after the participation tendency. There was a significant difference in sports participation tendency $(\mathrm{P}<0.05)$. After the intervention of the teaching method, the students' participation tendency was significantly higher than that before the intervention. However, the change in the control group was not obvious, and there was no significant difference in the tendency of exercise participation (P BBB 0.05). It shows that the experimental intervention is effective and improves the students' enthusiasm to participate in the basketball game. More students noticed the basketball game. Explain that competition law can improve students' participation tendency.

Table 2 List of avoidance tendencies $(n=40)$

\begin{tabular}{llccc}
\hline & $\mathrm{N}$ & $\mathrm{M}+\mathrm{SD}$ & $\mathrm{P}$ \\
\hline Experimental group & $\begin{array}{l}\text { Before you avoid } \\
\text { the tendency }\end{array}$ & 40 & $6.18 \pm 3.94$ & $<.85 \pm 3.00$ \\
$\begin{array}{l}\text { After the avoidance } \\
\text { of inclination }\end{array}$ & 40 & $6.20 \pm 3.89$ & \\
$\begin{array}{l}\text { Before you avoid } \\
\text { the tendency }\end{array}$ & 40 & $5.95 \pm 3.77$ & $>0.05$ \\
\hline $\begin{array}{l}\text { Efter the avoidance } \\
\text { of inclination }\end{array}$ & 40 & \\
\hline
\end{tabular}


It can be seen from table 2 that there was a significant change in the value of the boys' movement avoidance in the experimental group. There was a significant difference in movement avoidance tendency $(\mathrm{P}<0.05)$. After the students' intervention in the teaching method, the avoidance tendency was significantly lower than that before the intervention. The control group did not change significantly. There was no significant difference in sports participation tendency. It is shown that it is effective to interfere with students through competition law experiment teaching. After the intervention of the competition law students' avoidance tendency was significantly reduced. It shows that competition law can reduce students' tendency to avoid.

Through the results from the study we can find that the basketball sport motivation on tended to participate in and avoid all had significant difference, while the control group tended to participate in and avoid no significant sexual difference. Therefore, the competition law has a positive influence on the sports motivation of high school students. Verify the experimental hypothesis.

\section{Summary}

Based on the questionnaire, the data can be judged. The participation tendency of the experimental group had significant difference, while the participation tendency of the control group was not obvious. Through interviews with students after class, it was known that the main reasons for the low propensity of students before the experiment were: students' personal interests [2], basic technology not skilled, the opportunity to learn enough, afraid of his terrible afraid to participate [3], the limitation of space equipment [4].

By analyzing the data obtained after the experimental intervention, it can be found that the tendency of basketball avoidance tendency of the students in the experimental group decreased effectively. It is shown that the competition law can effectively improve students' basketball participation motivation and motivate students to learn. Through interviews with students, the students showed a good skill level in the competition, and practiced the skills of basketball. In this process, not only improve the students' own basketball skills, but also effectively improve students' self-confidence, thus achieving the promotion of participation [5]. On the other hand, judging by the game design and the actual game content. The game is not only a person's skill performance, but also needs the team's coordination to win the game. Through the team effect, the students with poor foundation and low confidence will be more active in learning and exercising in class and after class. When the athletic ability improves, can more actively participate in the basketball game [6]. Therefore, the tendency of participation is obviously improved, and the avoidance tendency has also changed significantly before and after the intervention [7].

After statistical analysis of the data before and after the experiment, it was found. In the experimental group, there was a significant difference between the participants' participation tendency and the avoidance tendency before and after the experiment. There was no significant change in the participation tendency and avoidance tendency of the control group. It shows that the game method is effective in improving the basketball motivation of high school students. The application of the competition method is conducive to satisfying the needs of the students to participate in the basketball game and to stimulate the motivation of sports. Connecting the content, methods and forms of basketball teaching with students' needs to stimulate students' interest in activities is conducive to the enhancement of students' motivation in sports learning [8].

\section{References}

[1] Yuan Xiao. Research on the application of "competition teaching method" to the public P.E. course in college basketball.Chengdu Institute of Physical Education,2013,2.

[2] Bo Qin. Analysis on the present situation and influencing factors of high school students ' participation in basketball in Xuzhou City. Contemporary Sports science and technology,2015,24,(5): 212. 
[3] Jingbo $\mathrm{Xu}$.A survey of Jiyuan teenagers ' participation in basketball motivation. Jiyuan Vocational and Technical College, 2011,2(10):124.

[4] Jike Gao. Study on Gannan Tibetan high school students ' interest in basketball sports. Northwest Normal University,2010,6:35-36.

[5] Wenhui Tan. Through the research and analysis of experimental teaching method. Adult education, 2010, 282: 89.

[6] Yi Luo.A survey of Meitan County High school students participating in basketball sports.Journal of Carey College, 2013, 3(31):186.

[7] Yuan Xiao. Research on the application of "competition teaching method" to the public P.E. course in college basketball. Chengdu Institute of Physical Education, 2013, 12: 23.

[8] Miao Zhang. Study on the motivation of Kunming students ' participation in basketball. Yunnan Normal University, 2006,6:39. 